Technical Reports

\title{
Well Test and PTA for Reservoir Characterization of Key Properties
}

\author{
${ }^{1}$ Okotie Sylvester, ${ }^{2}$ Ikporo Bibobra and ${ }^{3}$ Ogbarode Napoleon Ogbon \\ ${ }^{1,3}$ Department of Petroleum and Gas Engineering Federal, University of Petroleum Resources, Effurun, Nigeria \\ ${ }^{2}$ Department of Chemical and Petroleum, Niger Delta University, Amasoma, Nigeria
}

\author{
Article history \\ Received: 09-02-2015 \\ Revised: 02-03-2015 \\ Accepted: 13-10-2015 \\ Corresponding Author: \\ Okotie Sylvester \\ Department of Petroleum and Gas \\ Engineering, Federal University of \\ Petroleum Resources, Effurun, \\ Nigeria \\ Email: sterz_ok@yahoo.co.uk
}

\begin{abstract}
The characterization of a reservoir is a process which starts from the beginning of the field (oil or gas) discovery and continuous to the field's abandonment. It quantitatively or qualitatively describes the characteristics of the reservoir using data available. In the determination of key well and reservoir parameters for reservoir characterization, it is very vital to understand the flow phases and how to adequately identify them to prevent the challenge of obtaining the require parameters from a wrong phase. Thus, to successfully interpret a well test result either manually or by the use of computer aided software, we need to understand the well, reservoir and boundary models to actually match the field data. This success depends on the range and quality of pressure and rate data available and also the approach adopted for the analysis. This study adopted the method of pressure transient analysis, PTA to determine key well and reservoir parameters. A general well test work flow and the procedure for buildup test is presented. Data were obtained from Agba 8 and Ukot wells in the Niger Delta region of Nigeria and analyzed using well test analysis software 'saphir' to generate the damage and flow parameters around the wellbore. Result shows that Agba 8 well is a candidate well for stimulation operation due to positive skin.
\end{abstract}

Keywords: Reservoir Characterization, PTA, Well Test, Flow Phases, Reservoir Boundary, Well Test Interpretation, Drill Stem Tests, Stimulation

\section{Introduction}

Reservoir characterization is a process which starts from the beginning of the field (oil or gas) discovery and continuous to the field's abandonment. It quantitatively or qualitatively describes the characteristics of the reservoir using data available. On the other hand, transient well testing is one of the practical and indirect techniques to characterize wells and reservoirs properties whose interpretation contributes to the improvement of the understanding of the Geologic model. The success of the result obtained from well testing analysis is a function of the range and the quality of pressure and rate data available and also the approach used for the analysis. The application of the well test result helps the Explorationist to determine if the zone is economic and how large is the reservoir, it assist the Reservoir engineering team to describe this reservoir in order to estimate reserves, forecast future performance and optimize production. For the Production engineering team, it helps to identify if the wells drilled into the reservoir are damaged, how effective was the stimulation treatment and why are these wells not performing as expected.

Ilfi (2012) stated that transient well testing is good to be studied using generated data from reservoir simulation model. The reaction is simply recognized from pressure response by giving certain production or injection rate control. He also mention that; in order to generate sufficient well test data from simulation, the model has to be correctly designed close to its actual condition. One of parameter to be adjusted is the gridding system where Local Grid Refinement (LGR) plays an important role. He also did a work on pressure transient analysis using generated well test data from simulation of selected wells in Norne field, he mention that specific stage of reservoir discovery, development and production are dedicated to certain types of tests. 
Drill Stem Tests (DSTs) and wireline formation test are normally run in exploration and appraisal wells. During primary, secondary and enhanced recovery stages, the conventional transient well tests (i.e., drawdown, buildup, interference and pulse tests) are run. Step-rate, injectivity, falloff, interference and pulse tests are executed during secondary and enhanced recovery stages. Some tests are implemented throughout the life of reservoir, such as multilayer and vertical permeability tests (Kamal, 2009). In addition, in each type of test carried out, there are various information on the reservoir properties that can be obtained shown in Table 1 .

In modern graphical analyses, the uses of pressure derivative curves have become standard because the curves have greatest precision in the parts of the response of greatest interest and have easily identifiable characteristics. Basically, in the interpretation of well test; conventional method or type curves can be used for analysis and diagnoses. Bourdet et al. (1983) presents a most known set of type curves which simplifies well test analysis and diagnoses. Since the type curve as facilitated the interpretation and uniqueness of match introduced by Bourdet et al. (1983; 1989; Pirard and Bocock, 1986) is has been considered as a major breakthrough with the pressure derivative plot. While the application of the derivative to bounded reservoirs was presented by Proano and Lilley (1986). Horne (1994) has summarized modern approaches to well test analysis-using computers and Buhidma and Chu (1992) present state-of-the-art computer application of pressure transient analysis.

Djebbar and Henry (1979) shows a type curves matching technique for interpretation of the pressure transient behavior of wells located in various Multiple Sealing-fault systems because the presence of a fault in a reservoir is of great importance, considerable numbers of pressure analysis techniques dealing with this situation have been proposed in literature. Djebbar and Anil (1980) presents study on the behavior of a well located between two parallel boundaries. Stehfest (1970) presented a numerical inversion algorithm used to invert the Laplace space solution to real space. The analytical solution to diffusivity equation lead to generate Bessel equation, this equation makes use of Bessel functions, Abramowitz and Stegun (1970) present polynomial approximation to compute the modified Bessel function, Giovanni (1990).

\section{Flow Phases}

In the determination of key well and reservoir parameters for reservoir characterization, it is very vital to understand the flow phases and how to adequately identify them to prevent the challenge of obtaining the require parameters from a wrong phase. Practical when carrying out well test, three flow phases exists which are; the wellbore storage, transient state and the late time phase. Field operators try as much as possible to reduce the Wellbore Storage phase (WBS). The WBS represents the volume of the well that communicates with the tubing which may last so long that all the transient state phase may be polluted. Analysis can only be done on the transient state phase without concurrent WBS. This phase is mostly affected by the compressibility of the fluid in the well, production rate and the volume of the well that communicate with the tubing. Thus, the higher the production rate, the smaller the duration of the WBS; the higher the fluid compressibility which is dependent on the Gas-Oil Ratio (GOR) the higher the WBS. It should also be noted here that in buildup tests, if there are leaks possibly in the packer, the wellbore storage phase may not end. It is therefore recommended by professor Mike Onyekonwu in one of His well test lecture classes; that we use a downhole shut-in tool situations in wells with unusually long wellbore storage duration and also do not shut the well at the Flow station because it will take a longer time for the WBS to end.

Table 1. Reservoir properties obtained from various transient tests

\begin{tabular}{|c|c|}
\hline Types of tests & Data obtained \\
\hline Drill stem tests (DSTs) & $\begin{array}{l}\text { Reservoir behavior, fluid samples, permeability, skin, fracture length, reservoir pressure } \\
\text { and reservoir limit boundary }\end{array}$ \\
\hline Wireline formation tests & Presure profile, fluid samples and some reservoir properties \\
\hline Drawdown tests (DD) & Reservoir behavior, permeability, skin, fracture length and reservoir limit boundary \\
\hline Buildup tests (BU) & Reservoir behavior, permeability, skin, fracture length and reservoir pressure \\
\hline Step-rate tests & Formation parting pressure, permeability and skin \\
\hline Falloff tests & $\begin{array}{l}\text { Mobility in various banks, skin, reservoir pressure, fracture length and location of front } \\
\text { boundaries }\end{array}$ \\
\hline Interference and pulse tests & $\begin{array}{l}\text { Communication between wells, reservoir type behavior, porosity, interwell and vertical } \\
\text { permeability }\end{array}$ \\
\hline Layered reservoir tests & $\begin{array}{l}\text { Properties of individual layers, horizontal and vertical permeability, skin, average layer } \\
\text { pressure and outer boundaries }\end{array}$ \\
\hline
\end{tabular}


On the other hand, Transient State Phase (TSP) determines some of the key well and reservoir parameters such as skin and permeability and when running a well test, the TSP must be reached before the test is stopped. It is described as phase where pressure changes at the wells are not influenced by the nature of the boundary. In a well with high permeability, there is possibility of the WBS to completely destroy the TSP because the higher the permeability the shorter the TSP duration which makes analysis difficult. In addition, wells that are closer to the reservoir boundary will have shorter TSP with reason be that the well will hit the boundary faster than wells farther from the boundary. Finally, when the TSP ends, the Late Time Phase (LTP) starts since it does not occur concurrently with the TSP. this phase can develop to a steady and pseudo-state phase during a drawdown test and average pressure in a buildup test.

\section{Reservoir Boundary}

The size of the reservoir is important when estimating the amount of fluid recoverable from the reservoir. Therefore, the location and type of boundaries must be known. Therefore, to successfully interpret a well test result either manually or by the use of computer aided software such as sapphire used in this study, we need to understand the well, reservoir and boundary models presented in Table 2 to actually match the field data.

According to Dake (1978) and Horne (1995), the closed or no-flow boundaries imply that there is no flow through the reservoir boundaries, the pressure perturbation associated with production from a well will be transmitted outward until it reaches all sides of the boundary and enters a state known as pseudosteady state. The open boundaries mean that a constant pressure exists at the boundaries, that is, the reservoir is pressure supported by either an aquifer or by fluid injection. The effect of the constant pressure is known as steady state. Another intermediate state, transient state is usually observed before constant pressure or closed boundary effects are reached. In this case the reservoir behaves as if it was infinite for testing purposes. The more accurately the type and location of the boundaries can be predicted, the more accurately can the amount of recoverable fluid be calculated.

\section{The Statement of Problem/Objectives}

Every company wants to get to the reservoir as fast as they can, but they don't want to make it less productive by impairing permeability. This can be achieved if they know how to avoid the fluid-related causes of formation damage such as: Foreign particle invasion and plugging, formation clay dispersion and migration, chemically incompatible fluids, oil wetting of reservoir rock, emulsion and water blocking and fluid invasion etc. all these cannot be known without the help of well testing and pressure transient analysis. Furthermore, for every test conducted, there is an objective to be arrived but there are challenges of improper design of the test to meet objectives and moreso, the test duration too short to capture the transient phase where important parameters are determined, there is also the possibility of gauge failure and inability to identify flow regimes or reservoir model.

This study is basically carried out on Ukot and Agba 8 wells to determine key well and reservoir parameters such as permeability and skin to know if the wells are damaged or ascertain the success of stimulation jobs with the use of well test analysis software "saphir". The results will help to properly characterize the reservoir for an effective reservoir management, candidate well selection for stimulation, an input data for reservoir simulation and also for production surveillance.

\section{Methodology}

This study adopted Pressure Transient Analysis (PTA) to achieve the objectives of the study. The general well test work flow is presented in Fig. 1 and the procedure for buildup test to determine key well and reservoir parameters is given in appendix A and the work flow in Fig. 2. Data were obtained from Agba 8 and Ukot wells in the Niger Delta region of Nigeria and analyzed using well test analysis software 'saphir' to generate the damage and flow parameters around the wellbore.

Table 2. Well/reservoir/boundary models

\begin{tabular}{lll} 
Table 2. Well/reservoir/boundary models & Reservoir models & Boundary models \\
\hline Wellbore storage and skin & Homogeneous & Closed \\
Changing wellbore storage & Single fracture & Constant \\
Well on a fracture & Double porosity & Fault (single or parallel) \\
Horizontal well & composite & Leaky fault \\
Limited entry well & & \\
\hline
\end{tabular}




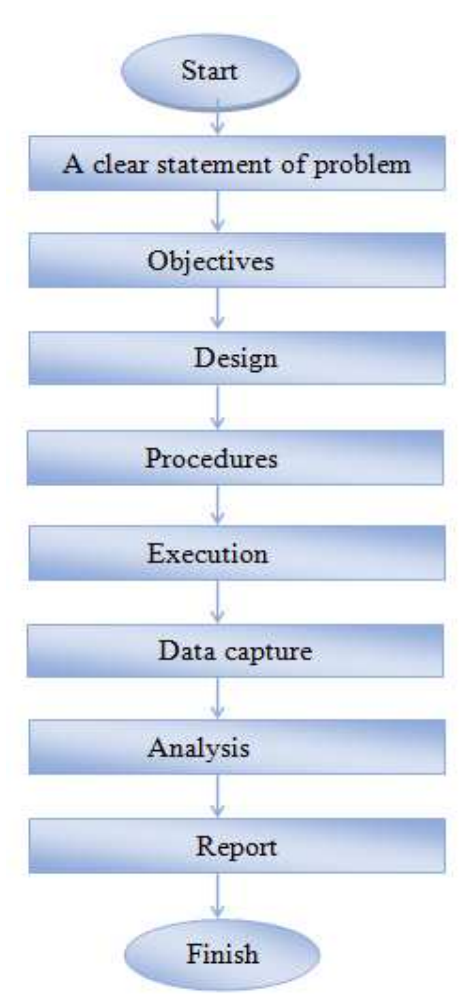

Fig. 1. Well test work flow

\section{General Data Requirements}

- Well/Reservoir History

- Deviation survey

- Reservoir Datum Depth( for datum pressure correction)

- $\quad$ PVT report (FVF, $\mu, \mathrm{C}_{\mathrm{o}}, \mathrm{C}_{\mathrm{w}}, \mathrm{C}_{\mathrm{g}}$ or $\mathrm{C}_{\mathrm{t}}$ )

- Petrophysical Data $\left(h, S_{w}, S_{0}, S_{g}, \phi\right.$, reservoir top and bottom)

- Core, log data (to check homogeneity, porosity, dual porosity, OWC, GWC etc.)

- RFT, pressure depth profiles (to check pressure equilibrium and thus homogeneity)

- Drive mechanism

- Geological Data ( Top and bottom structure Maps, Geologic detail of the formation, well position relative to boundary and position of OWC, GOC)

- Well Schematics (perforation details, well radius)

- Bottom hole pressure gauges' data (Time, Pressure and Temperature) At least 2 gauges per survey

- Well flow rates prior to and during the test

\section{Input Data into the Software (Saphir)}

Table 3 to 5 show the well and reservoir data of Ukot and Agba 8 well, Ukot well Rate profile and Schedule of Agba 8 respectively.

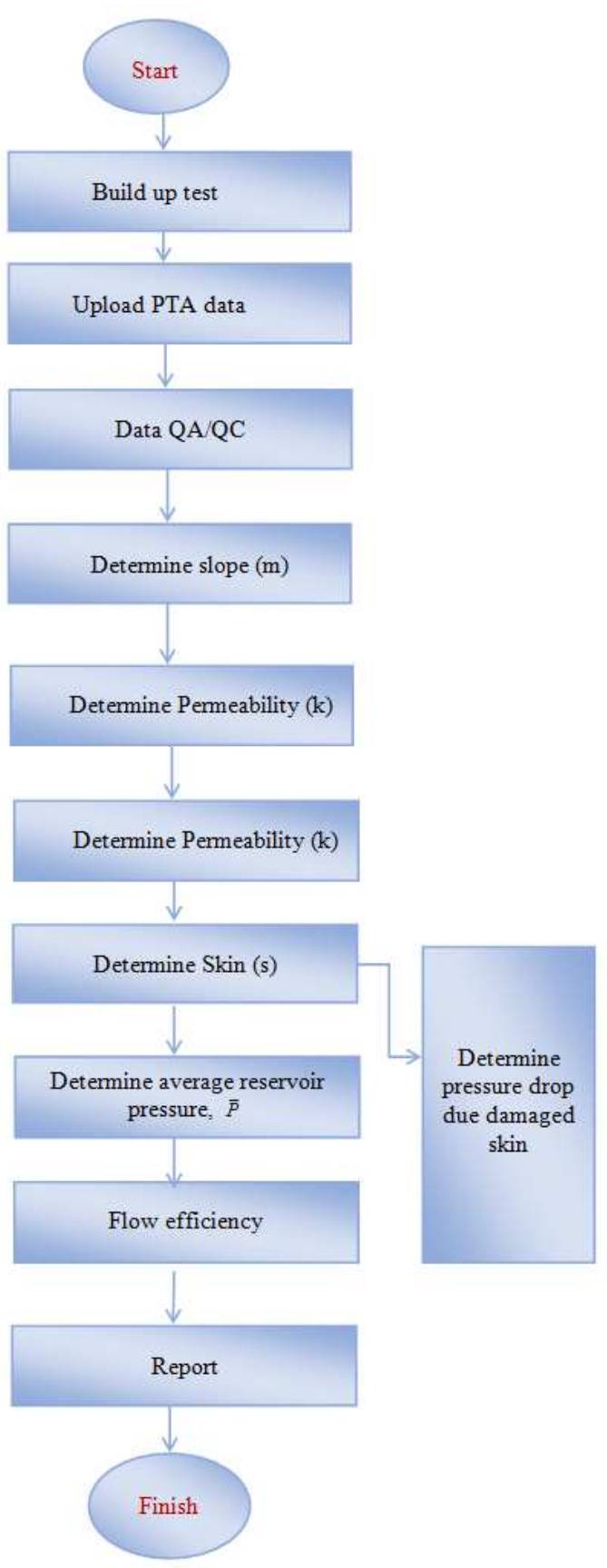

Fig. 2. Buildup test work flow

\section{Result of Ukot Well}

Ukot well was analyzed as oil well and the data are given in Table 3-5. The test was conductor for 2 days and ukot well on 2/16/2001 at 19:00:00 time of the day was producing with a rate of $1650 \mathrm{STB} / \mathrm{D}$ for $16 \mathrm{~h}$ before the rate was increased to 2300 for another $10.11 \mathrm{~h}$ before it was shut-in at 21:07:10 the next day for pressure build. $9.61 \mathrm{~h}$ on that same day, the well was open for 
production with a rate of $1650 \mathrm{STB} / \mathrm{D}, 3 \mathrm{~h}$ later rate was reduced to $720 \mathrm{ST} / \mathrm{D}$ before it was shut-in. Four pressure gauges were used during the test period to test for

Table 3. Well and reservoir data of Ukot and Agba 8well

\begin{tabular}{|c|c|c|}
\hline \multirow[b]{2}{*}{ Parameter } & \multicolumn{2}{|l|}{ Value } \\
\hline & Ukot well & Agba 8 well \\
\hline Porosity & 0.33 & 0.12 \\
\hline $\mathrm{Ct}, \mathrm{psi}-1$ & $10^{-5}$ & $3 \mathrm{E}-6 \mathrm{psi}-1$ \\
\hline Reservoir thickness, $\mathrm{ft}$ & 45 & $34 \mathrm{ft}$ \\
\hline Wellbore radius, rw, $\mathrm{ft}$ & 0.265 & $0.29 \mathrm{ft}$ \\
\hline Formation volume factor $\mathrm{rb} / \mathrm{stb}$ & 1.078 & $1.25 \mathrm{~B} / \mathrm{STB}$ \\
\hline Oil viscosity, $\mathrm{cp}$ & 0.31 & $0.58 \mathrm{cp}$ \\
\hline Perforations, ft, (MD) & $3771-4599$ & \\
\hline Total perforated length, $\mathrm{ft}$ & 1531 & \\
\hline Pump depth, ft, (MD)/TVD (SS) & $1965 / 1817$ & \\
\hline Gauge depth, ft, (MD)/TVD (SS) & $3771 / 2583$ & \\
\hline Bottom hole temperature ${ }^{\circ} \mathrm{F}$ & 155 & \\
\hline Rate, bbl/d & 1500 & \\
\hline API gravity & 18.5 & \\
\hline Shut in time & $310 \mathrm{~h}$ & \\
\hline
\end{tabular}

consistency in result of pressure values and Fig. 3 shows that these gauges are consistent in reading from the pressure difference plot.

Table 4. Ukot well rate profile

\begin{tabular}{llll}
\hline Date & ToD & Liquid rate STB/D & Duration hr \\
\hline $2 / 16 / 2001$ & $19: 00: 00$ & 1650 & 16.0056 \\
$2 / 17 / 2001$ & $11: 00: 20$ & 2300 & 10.1139 \\
$2 / 17 / 2001$ & $21: 07: 10$ & 0 & 10.7361 \\
$2 / 18 / 2001$ & $7: 51: 20$ & 1650 & 9.61389 \\
$2 / 18 / 2001$ & $17: 28: 10$ & 720 & 3.03889 \\
$2 / 18 / 2001$ & $20: 30: 30$ & 0 & 2.5 \\
\hline
\end{tabular}

Table 5. Schedule of Agba 8

\begin{tabular}{lll}
\hline First shut-in period & $5.47 \mathrm{~h}$ & Stimulating well \\
\hline First pumping period & $5 \mathrm{~min}$ & Using submersible pump \\
Second shut-in period & $9.25 \mathrm{~h}$ & Take out plug at 19163 (MD) and BHP guage to 2182 (MD) \\
Second pumping period & $8.08 \mathrm{~h}$ & Using submersible pump \\
First shut-in period & $12.08 \mathrm{~h}$ & Build up test \\
\hline
\end{tabular}

Table 6. Result from saphir (Ukot Well)

\begin{tabular}{|c|c|c|c|}
\hline Gauge 1 build-up \#1 & Model parameters & Well and wellbore parameters (Moliere 1) & \\
\hline Rate & $0 \mathrm{STB} / \mathrm{D}$ & $\mathrm{C}$ & $0.00299 \mathrm{bbl} / \mathrm{psia}$ \\
\hline Rate change & $2300 \mathrm{STB} / \mathrm{D}$ & Skin & -3.73 \\
\hline $\mathrm{P} @ \mathrm{dt}=0$ & 3086.62 psia & Reservoir and boundary parameters & \\
\hline $\mathrm{Pi}$ & 3597.35 psia & $\mathrm{Pi}$ & 3597.35 psia \\
\hline Smoothing & 0.1 & k.h & 2520 md.ft \\
\hline Select model & $\mathrm{K}$ & $74 \mathrm{md}$ & \\
\hline Model option & Standard Model & $\mathrm{L}$ & $287 \mathrm{ft}$ \\
\hline Well & vertical & Leakage & 0.507397 \\
\hline Reservoir & homogeneous & Derived and secondary parameters & \\
\hline Boundary & Leaky fault & Delta P (Total skin) & $-348.959 \mathrm{psi}$ \\
\hline Main model parameters & Delta P Ratio (Total Skin) & -0.762749 & \\
\hline TMatch & $428[\mathrm{~h}]^{-1}$ & & \\
\hline PMatch & 0.0107 [psia] $^{-1}$ & & \\
\hline $\mathrm{C}$ & $0.00299 \mathrm{bbl} / \mathrm{psia}$ & & \\
\hline Total skin & -3.73 & & \\
\hline k.h, total & $2520 \mathrm{md} . \mathrm{ft}$ & & \\
\hline $\mathrm{K}$, average & $74 \mathrm{md}$ & & \\
\hline $\mathrm{Pi}$ & 3597.35 psia & & \\
\hline
\end{tabular}




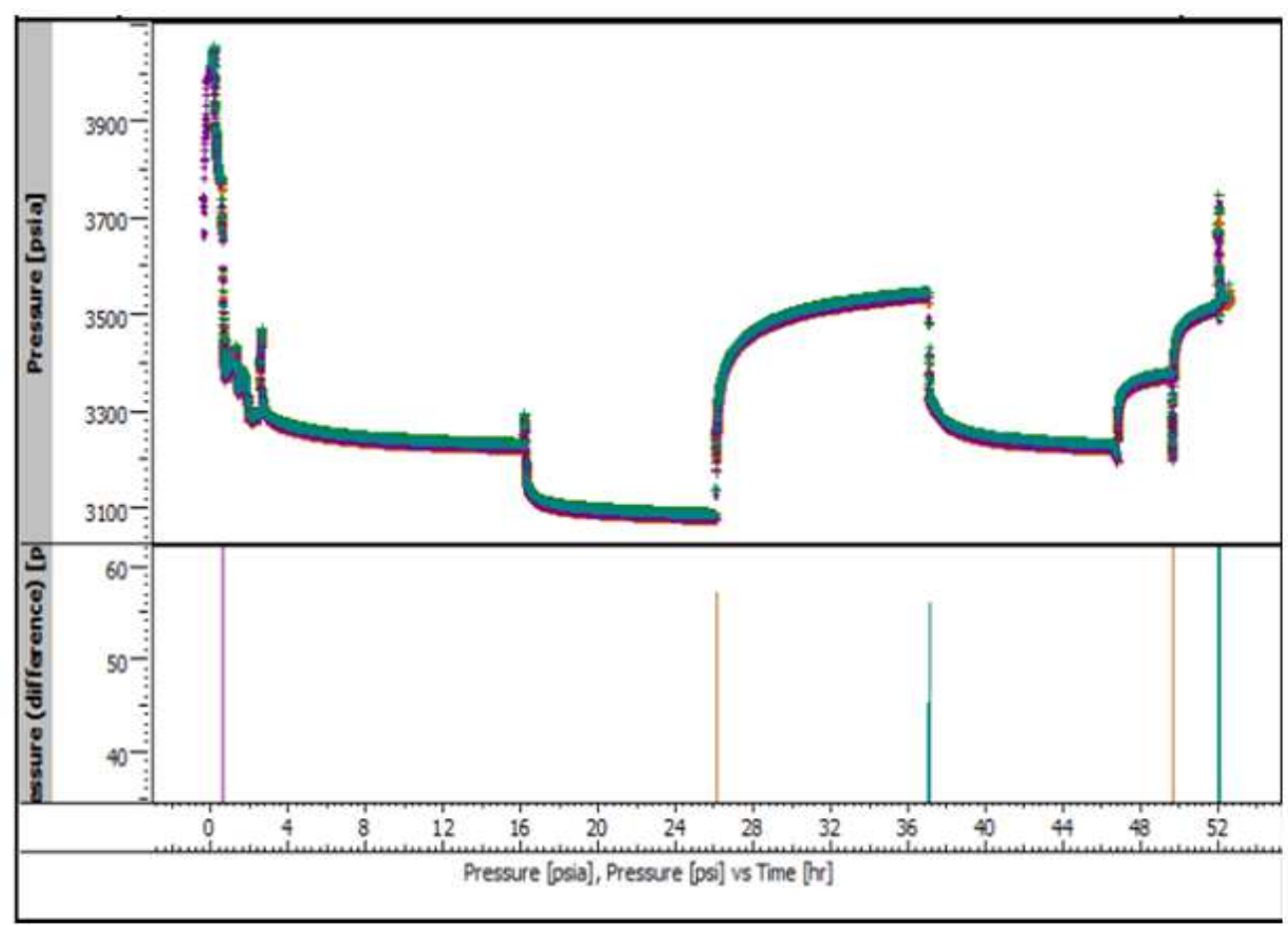

Fig. 3. Pressure gauges synchronization

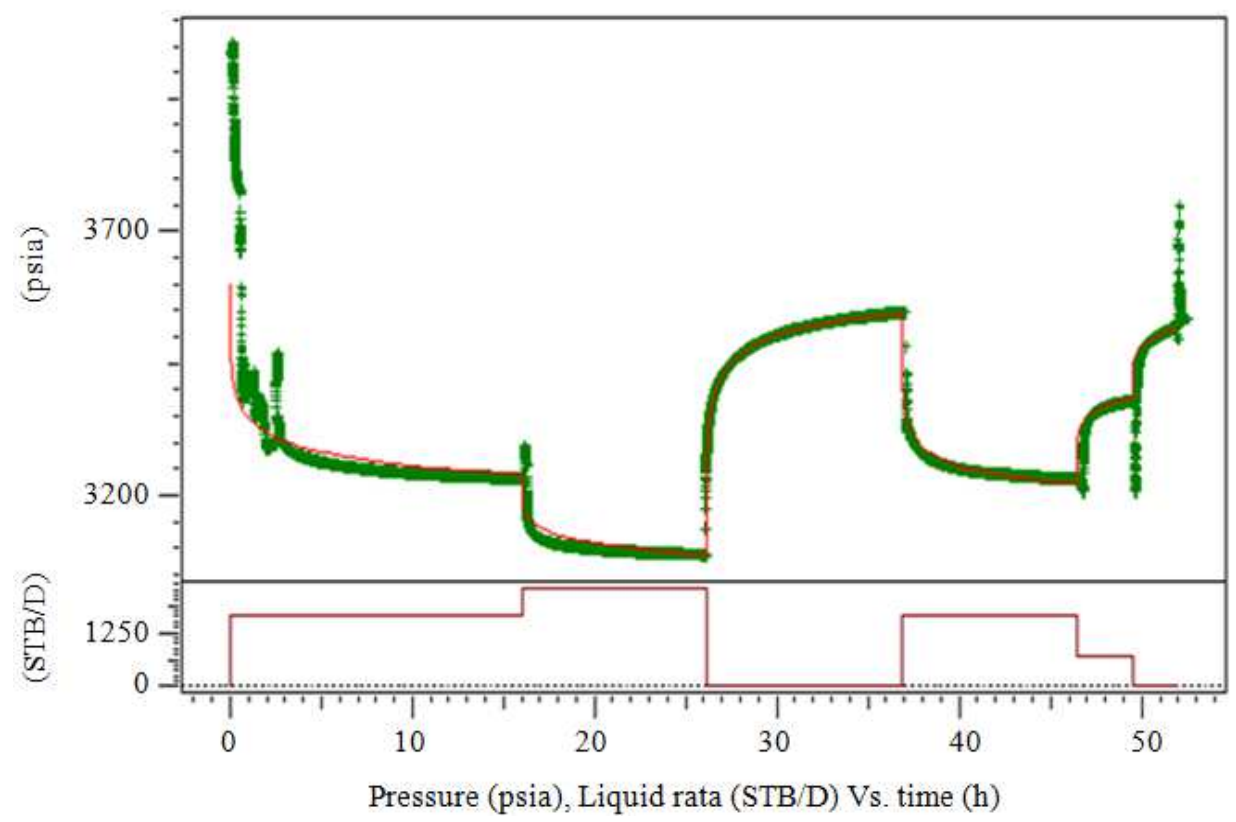

Fig. 4. Rate and pressure profile of Ukot well

The rate and pressure profile of Ukot well (Fig. 4) indicates two build period and multi-rate draw down prior to shut-in in the first build from the test result. Though the second build did not take longer time and thus, analysis was made using the first build up period. The result generated using well test analysis software,
Saphir is given (Fig. 5). Several reservoir and boundary models were selected to actually match the field data and in the end, a homogenous reservoir model with leaky fault boundary was preferred which fits the field data. The skin shows that the well is not damaged and it is not recommend for stimulation (Table 6). 
Okotie Sylvester et al. / American Journal of Engineering and Applied Sciences 2015, 8 (4): 638.647 DOI: 10.3844/ajeassp.2015.638.647

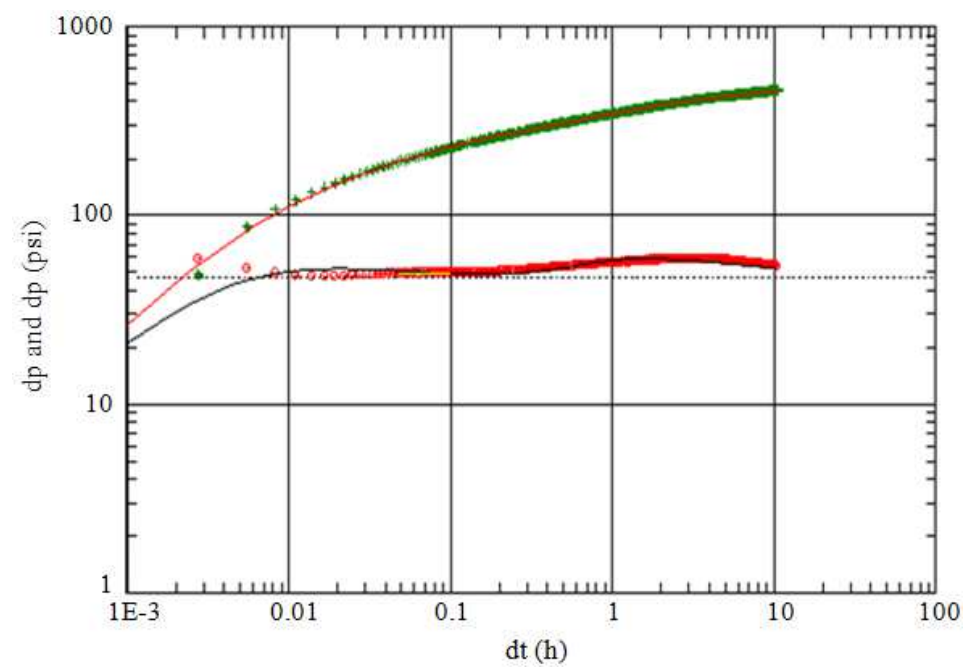

Fig. 5. Log-log model of Ukot well

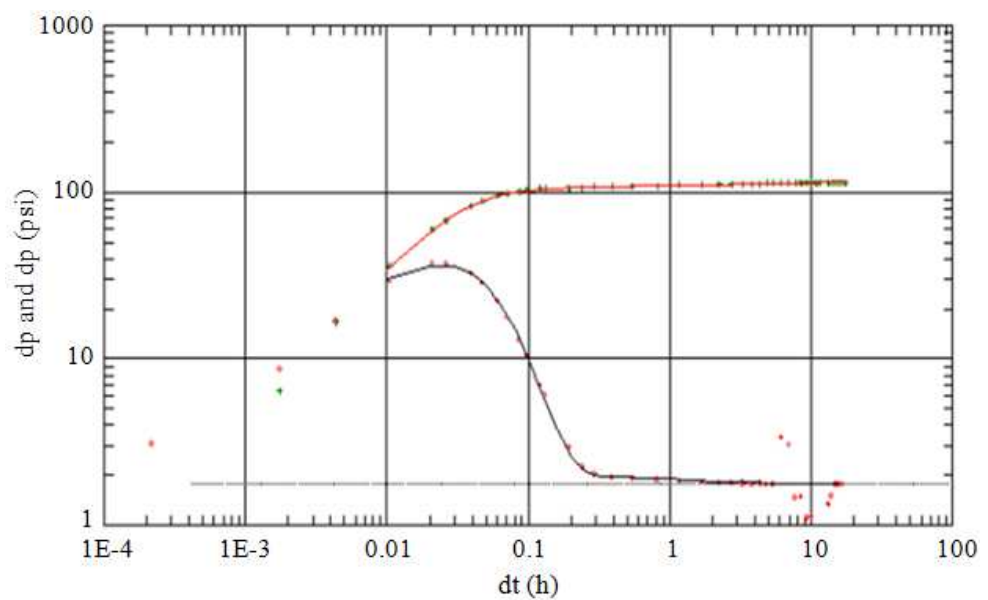

Fig. 6. Log-log output result of Agba 8

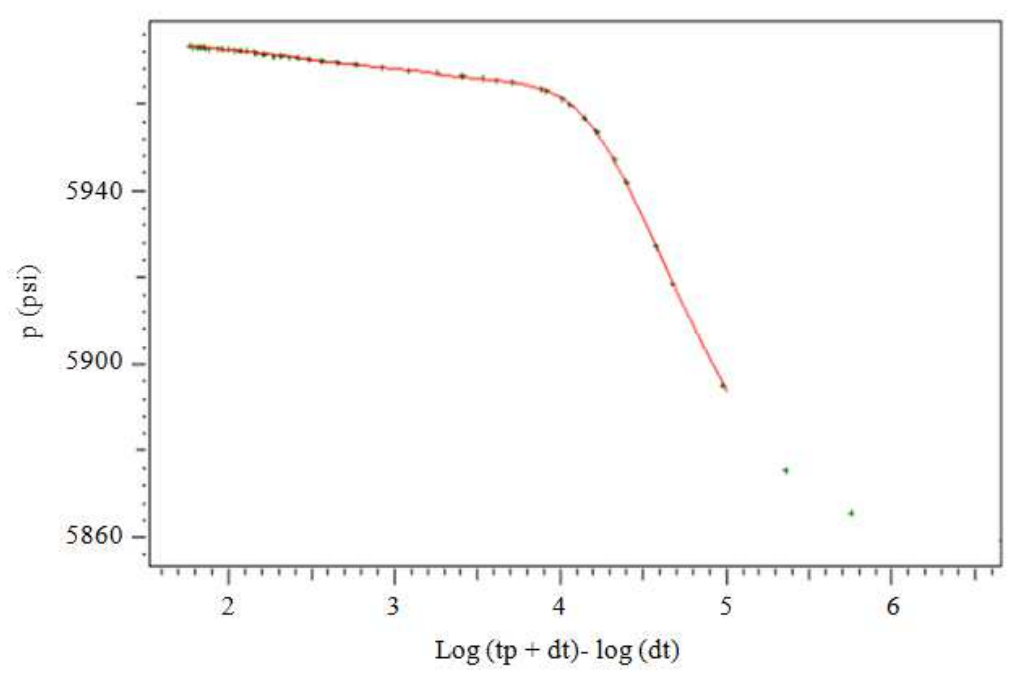

Fig. 7. Semi-log plot of Agba 8 


\begin{tabular}{|c|c|c|c|}
\hline Gauge 1 build-up \#1 & Model parameters & Well and wellbore parameters (Tested well) & \\
\hline Rate & $0 \mathrm{STB} / \mathrm{D}$ & $\mathrm{C}$ & $0.0175 \mathrm{bbl} / \mathrm{psia}$ \\
\hline Rate change & $1500 \mathrm{STB} / \mathrm{D}$ & Skin & 22.4 \\
\hline $\mathrm{P} @ \mathrm{dt}=0$ & 5859.08 psia & Reservoir and boundary parameters & \\
\hline $\mathrm{Pi}$ & 5980.62 psia & $\mathrm{Pi}$ & 5980.62 psia \\
\hline Smoothing & 0.1 & k.h & 39200 md.ft \\
\hline Select model & $\mathrm{K}$ & $872 \mathrm{md}$ & \\
\hline Model option & Standard model & Omega & $6.45 \mathrm{E}-4$ \\
\hline Well & vertical & Lamda & $4.33 \mathrm{E}-6$ \\
\hline Reservoir & Two porosity sphere & Derived and secondary & parameters \\
\hline Boundary & Infinite & Delta P (total skin) & $79.8925 \mathrm{psi}$ \\
\hline Main model parameters & Delta $P$ ratio (total skin) & 0.699157 & \\
\hline TMatch & $1180[\mathrm{hr}]^{-1}$ & & \\
\hline PMatch & $0.28\left[\mathrm{psia}^{-1} 1\right.$ & & \\
\hline $\mathrm{C}$ & $0.0175 \mathrm{bbl} / \mathrm{psia}$ & & \\
\hline Total skin & 22.4 & & \\
\hline k.h, total & $39200 \mathrm{md} . \mathrm{ft}$ & & \\
\hline $\mathrm{K}$, average & $872 \mathrm{md}$ & & \\
\hline $\mathrm{Pi}$ & 5980.62 psia & & \\
\hline
\end{tabular}

\section{Agba 8 Well Result}

From the pressure transient analysis to determine the Agba 8 skin and permeability using saphir as show in the Fig. 6 and 7. This data is actual a buildup test, which implies that the well must have been flowing for a long time before it was shut-in for the buildup test. Result obtained when these data were inputted into the well test analysis software shows that the wellbore storage constant is $0.0175 \mathrm{bbl} / \mathrm{psi}$, skin is 22.4; permeability of $872 \mathrm{mD}$, the capacity is 39200 $\mathrm{mD}-\mathrm{ft}$ and initial pressure of $5980.62 \mathrm{psia}$. This is an indication of damage as a result of the positive skin. Hence requires a stimulation job to remove the damage (Table 7).

\section{Conclusion}

Well test analysis has come a long way since the 1950s when the interpretation methods on the basis of straight lines gave unreliable results.

The derivative approach improves the definition of the analysis plots and therefore the quality of the interpretation. The differentiation of actual data has to be conducted with care to remove noise without affecting the signal. The derivatives approach does not produce errors or noise but only reveals them. The interpretation of pressure derivative is a single-plot procedure. If enough data are available, pressure and time matches are fixed, so analysis is faster. This is important for real-time interpretation during well-test monitoring.

The well interpretation of all the three wells had been presented in the previous chapter and result show that well Ukot and J5 wells are not damaged and do not require stimulation job since they gave negative skin value. Agba 8 is a candidate well for stimulation with a high positive skin value. Thus, characterization of a reservoir is very important for field development study.

\section{Acknowledgment}

The authors gratefully appreciate the management and staff of Ukot and Agba Fields for providing the data, support and permission to publish this work and also the anonymous reviewers and the editor for their valuable comments and insightful suggestions to improve this study.

\section{Funding Information}

The funding is done by the contribution of all authors.

\section{Author's Contributions}

Okotie Sylvester: Participated in the data QA/QC, development of study methodology, model build with saphir and contributed to the writing of the manuscript. Also updated reviewers' comments.

Ikporo Bibobra: Participated in the collection of data and contributed to the writing of the manuscript.

Ogbarode Napoleon Ogbon: Participated in the collection of data and contributed to the writing of the manuscript.

\section{Ethics}

This article is original and contains unpublished material. The corresponding author confirms that all of the other authors have read and approved the manuscript and no ethical issues involved. 


\section{References}

Abramowitz, M. and I.A. Stegun, 1970. Handbook of Mathematical Functions: with formula graphic and mathematical tables. National Bureau Standards, 231: 378-379

Bourdet, D., J.A. Ayoub and Y.M. Pirard, 1989. Use of pressure derivative in Well Test Interpretation. SPEFE, 4: 293-302.

Bourdet, D., T.M. Whittle, A.A. Douglas and Y.M. Pirard, 1983. A new set of type curves simplifies well test analysis. World Oil.

Buhidma, I.M. and W.C. Chu, 1992. The use of computers in pressure transient analysis. Proceedings of the SPE Annual Technical Conference and Exhibition, Oct. 4-7, Society of Petroleum Engineers, Washington, D.C., pp: 723-734. DOI: $10.2118 / 24730-M S$

Dake, L.P., 1978. Fundamentals of Reservoir Engineering. 5th Edn., Elsevier, Amsterdam, ISBN-10: 0444416250, pp: 443.

Djebbar, T. and K. Anil, 1980. Detection and location of two parallel sealing Faults around a well. J. Petroleum Technol., 32: 1701-1708.

Djebbar, T. and B.C. Henry, 1979. Pressure analysis of multiple-sealing-fault systems and bounded reservoirs by type-curve matching. Society Petroleum Engineers J., 19: 378-392. DOI: 10.2118/6755-PA

Giovanni. D.P., 1990. Well Test Analysis for Fractured Reservoir Evaluation. 1st Edn., Elsevier, New York, ISBN-10: 0080868851, pp: 209.

Horne, R.N., 1994. Advances in computer-aided well test Interpretation. J.of Petroleum Technol., 46: 599606. DOI: 10.2118/24731-PA

Horne, R.N., 1995. Modern Well Test Analysis: A Computer-Aided Approach. 2nd Edn., Petroway Inc., USA, pp: 257.

Ilfi, B.E.Y., 2012. Pressure transient analysis using generated well test data from simulation of selected wells in norne field. Norwegian University of Science and Technology, Trondheim.

Kamal, M.M., 2009. Transient Well Testing. 1st Edn., Society of Petroleum Engineers, Richardson, TX., ISBN-10: 978-1-55563-141-3, pp: 850.

Pirard, Y.M. and A. Bocock, 1986. Pressure derivative enhances use of type curves for the analysis of well tests. Proceedings of the International Meeting on Petroleum Engineering, Mar. 17-20, Society of Petroleum Engineers, Beijing, China, pp: 641-641.

Proano, E.A. and I.J. Lilley, 1986. Derivative of pressure: Application to bounded reservoir interpretation. Proceedings of the European Petroleum Conference, Oct. 20-22, Society of Petroleum Engineers, London, United Kingdom, pp: 137-143.
Stehfest, H., 1970. Numerical Inversion of Laplace Transforms. Commun. ACM, 3: 171-173.

DOI: $10.1145 / 367149.367172$

\section{Appendix A}

\section{Procedure for Analyzing Buildup Test}

Calculation of Wellbore Storage Constant Locate pressure influenced by wellbore storage effect. How?

- $\quad$ Make a graph of $D p=\left[P_{w s}-P_{w f}\left(t_{p}\right)\right]$ - versus $D t$ on a log-log paper

- Locate data with strong wellbore storage effect on the unit slope line

- Calculate the wellbore storage constant, Cs, using $D p$ and $D t$ from a point on the unit slope line and the following equation:

$$
C_{s}(r b / p s i)=\frac{q B}{24}\left[\frac{t}{\Delta P}\right]_{\text {unit slope }}
$$

- Locate the data not strongly influenced by wellbore storage effect. Use the gentle slope rule or the 10 $\mathrm{Dt}^{*}$ ( 1 cycle) to $50 \mathrm{Dt} * 1.5$ cycle) rule

\section{Calculation of Permeability}

\section{MDH Plot}

$$
P_{w s}=\bar{P}+\frac{162.6 q \beta \mu}{k h}\left[\log \Delta t+\log \left(\frac{0.000264 k}{\varnothing \mu C_{t} r_{w}{ }^{2}}\right)+\log \frac{C_{A} r_{w}{ }^{2}}{A}\right]
$$

Plot $P_{w s}$ versus $\log D t$. Use a semilog paper with time graphed on the log scale axis.

With the knowledge of the time when wellbore storage effect has died down completely, put the correct straight line that represents the good transient state behavior.

Determine the slope of the semilog straight line, $m$ and calculate the permeability using the equation:

$k=\frac{-162.6 q \beta \mu}{m h}$

At the end of this step, move to Step 8 to calculate skin factor.

\section{Horner Plot}

For infinite reservoir:

$$
P_{w s}=P_{i}-\frac{162.6 q \beta \mu}{k h} \log \frac{t_{p}+\Delta t}{\Delta t}
$$


For finite reservoir:

$P_{w s}=P^{*}-\frac{162.6 q \beta \mu}{k h} \log \frac{t_{p}+\Delta t}{\Delta t}$

Plot $\mathrm{P}_{\mathrm{ws}}$ versus. $\log \frac{t_{p}+\Delta t}{\Delta t}$

Use a semilog paper with Horner time graphed on the $\log$ scale axis. The graph can be made with Horner time increasing from left to right to left. The later is usually preferred as it gives a graph with shut-in time increasing from left to right.

With the knowledge of the time when wellbore storage effect has died down completely, put the correct straight line that represents the good transient state behaviour.

Determine the slope of the semilog straight line, $\mathrm{m}$ and calculate the permeability.

Extrapolate the straight line to Horner time equal to 1 (infinite shut-in time) and read off $\mathrm{P}^{*}$ or Pi. They are needed for estimating the average pressure in a well that was not shut in long enough to reach average pressure.

\section{Calculation of Skin}

The correct equation is given as:

$$
S=1.151\left\{\frac{P_{1 h r}-P_{w f}\left(t_{p}\right)}{m_{1}}-\log \frac{k}{\varnothing \mu C_{t} r_{w}^{2}}+3.232\right\}
$$

\section{Calculation of Flow Efficiency}

$$
F E=\frac{P_{i}-P_{w f, t=0}-(\Delta P)_{s k i n}}{P_{i}-P_{w f, t=0}}
$$

\section{Calculation of Average Reservoir Pressure}

$\bar{P}=P^{*}-\frac{m}{2.303} P_{D M B H}\left(t_{P D A}\right)$

Depends on reservoir geometry well location, $P_{D M B H}$ can be calculated as:

$$
\begin{aligned}
& P_{D M B H}=4 \pi t_{P D A}\left(t_{P}<t_{p s s}\right) \\
& P_{D M B H}=\ln C_{A} t_{P D A}\left(t_{P} \geq t_{p s s}\right) \\
& t_{P D A}=\frac{0.000264 k t_{P}}{\varnothing \mu A C_{t}}
\end{aligned}
$$

